\title{
Validation of acute physiology and chronic health evaluation (APACHE) IV score in a Korea provincial ICUS by comparing Korean simplified acute physiology score (SAPS) III
}

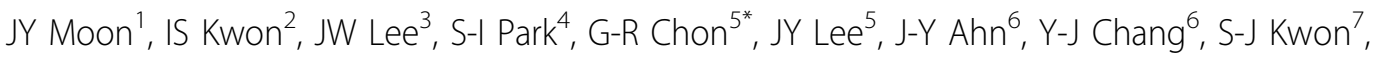 \\ Korean Chungcheong Critical Care Research Group (KCCCRG)
}

From ESICM LIVES 2015

Berlin, Germany. 3-7 October 2015

\section{Introduction}

The Simplified Acute Physiology Score (SAPS) III has been validated as the Korea SAPSIII model in Korea. However, the Acute Physiology and Chronic Health Evaluation (APACHE) IV model has not yet been validated in Korea provincial intensive care units (ICUs).

\section{Objectives}

The aim of this study was to compare the ability of the APACHE IV with Korean SAPS 3 in predicting hospital mortality in a provincial ICU population.

\section{Methods}

The study was designed as a prospective cohort study for patients admitted to the nine intensive care units in the four provincial academic medical centers from September 2013 to February 2014. Validation and comparison were conducted to measure discrimination and calibration with using the area under the receiver operating characteristic curve (AUC) and the Hosmer-Lemeshow test, respectively.

\section{Results}

Among 733 enrolled patients, 34.4\% (252/733) were surgical patients. The hospital mortality was $23.5 \%$. The median APACHE IV score was 71(Standard deviation \pm 33.8 ), and the predicted death rate was $25.6 \%$ respectively. The observed hospital mortality was $23.5 \%$. The discriminative powers of two models were similar. The

${ }^{5}$ Chungju Hospital, Konkuk University School of Medicine, Internal Medicine, Chungju, Korea, Republic of Korea

Full list of author information is available at the end of the article
AUCs were 0.753 (95\% confidence intervals (CI) : 0.7110.794) for APAPCH IV and 0.768 (95\% CI : 0.727-0.809) for Korean SAPS III respectively. Hosmer-Lemeshow C and $\mathrm{H}$ statics showed good calibration for both models, $(\mathrm{H}=8.69, \mathrm{p}=0.370 ; \mathrm{C}=128.17, \mathrm{p}=0.824$ for APACHE $\mathrm{IV}$, and $\mathrm{H}=8.40, \mathrm{p}=0.396 ; \mathrm{C}=178.98, \mathrm{p}<0.001$ for Korean SAPS III respectively).

\section{Conclusions}

For Korea regional ICU patients, the APACHE IV and Korea SAPS III showed good discrimination and good calibration for hospital mortality. Therefore, the APACHE IV prognostic model might be applied to predict mortality in Korea regional ICUs.

\section{Authors' details}

${ }^{1}$ Chungnam National Univ. Hospital, Internal Medicine, Daejeon, Korea, Republic of Korea. ${ }^{2}$ Chungnam National Univ. Hospital, Clinical Trials Center, Daejeon, Korea, Republic of Korea. ${ }^{3}$ Chungnam National University Hospital, Daejeon Regional Emergency Center, Daejeon, Korea, Republic of Korea. ${ }^{4}$ Chungnam National University Hospital, Anesthesiology and Pain Medicine, Daejeon, Korea, Republic of Korea. ${ }^{5}$ Chungju Hospital, Konkuk University School of Medicine, Internal Medicine, Chungju, Korea, Republic of Korea. ${ }^{6}$ Chungbuk National Univ. Hospital, Internal Medicine, Cheongju, Korea,

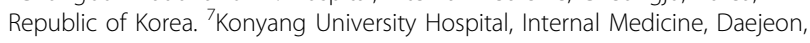
Korea, Republic of Korea.

Published: 1 October 2015

\section{References}

1. So Yeon Lim, et al: Validation of SAPS3 Admission Score and Its Customization for Use in Korean ICU Patients: A Prospective Multicenter Study. Respirology 2013, 18(6):989-995.

2. Jae Yeol Kim, et al: External Validation of the Acute Physiology and Chronic Health Evaluation II in Korean Intensive Care Units. Yonsei Med J 2013, 54(2):425-431. 
3. Hosmer DW, Lemeshow S: Confidence interval estimates of an index of quality performance based on logistic regression models. Stat Med 1995, 14:2161-2172.

4. Hannah Lee, et al: Validation of the APACHE IV model and its comparison with the APACHE II, SAPS 3, and Korean SAPS 3 models for the prediction of hospital mortality in a Korean surgical intensive care unit. Korean I Anesthesiol 2014, 67:115-122.

doi:10.1186/2197-425X-3-S1-A335

Cite this article as: Moon et al.: Validation of acute physiology and chronic health evaluation (APACHE) IV score in a Korea provincial ICUS by comparing Korean simplified acute physiology score (SAPS) III. Intensive Care Medicine Experimental 2015 3(Suppl 1):A335.

\section{Submit your manuscript to a SpringerOpen ${ }^{\circ}$ journal and benefit from:}

- Convenient online submission

- Rigorous peer review

- Immediate publication on acceptance

- Open access: articles freely available online

- High visibility within the field

- Retaining the copyright to your article

Submit your next manuscript at $\gg$ springeropen.com 